\title{
IMPACT OF PLACEMENT AND DISPLACEMENT / INSTITUTIONS OVER CAREER DEVELOPMENT IN PAKISTAN
}

\author{
Qandeel Ali \\ Ms, University of Islamabad, Pakistan, qandeelali600@gmail.com
}

\begin{abstract}
The primary purpose of this research was to describe the impact of placement and displacement in student's occupational and educational aspirations. A secondary purpose was to explore the relationship of the student's cultural background and its impact on their career development. The present social and economic scenarios in the third world countries have drawn the attention of world powers. These under developed countries are under huge foreign debts on one hand and have social chaos on the other hand. The short comings have given birth to extremism, fanaticism and terrorism. The educational institutions, to some extent, failed to promote coherence and national integration. The indifferent role of the state cannot be overlooked in enhancing these unwanted tendencies and the masses. The diversity in the education system and non-patronage by the state has deprived a handsome population of getting the quality education and finding appropriate career development opportunities.

The classification of the educational system and different groups such as government sector institutions, public sectors institutions, Oxford level Institutions, Cambridge level Institutions, Religious "Madras" and Maktab schools have created different groups in the society. The elimination of the extremist's tendencies is the dire need of the hour. So to give tranquility and peace to the world nations, institutions should play their role to take bold steps towards bringing standard course contents in all educational institutes. In order to develop the quality culture in institutions through external evaluation is essential. To address these challenges there is a need for a robust quality education in institutions.

Individuals with a rural background are facing difficulty in getting an education from quality institutions and having no access to multinational companies, whereas individuals with urban background have better placement or exposed to quality education and reputed companies for better career development.
\end{abstract}

Keywords: Social and Economic Scenarios, Quality Education System.

\section{INTRODUCTION}

The term placement and displacement pertain to the cultural background of a student. A student placed in an urban area having an access to quality education will have a better social, economic background, while a student displaced by birth and living in rural areas where the educational, social and economic facilities are limited. Such students are handicapped by their rural cultural background. Specifically, the term placement is for those who are living in rural areas. 
Education is proving to be an effective instrument that can raise students 'self-belief', 'fore thought', 'selfesteem' and 'self-efficacy'. Students living in undeveloped areas try to attain the best education but do not make their living environment better as the placement becomes a barrier to their success.

The economic disparity is highest in rural areas of Pakistan due to Landlord system. On one hand, the term placement and displacement play a vital role in the exchange of taboos but on the other hand, it also separates and promotes the feelings of discrimination. Education is one of the most powerful mechanisms known for reducing poverty, inequality and laying the basis for sustained monetary growth. It raises the competence and efficiency of individuals and produces skilled manpower that is proficient in leading economic development. Education is a process through which the intellectual, moral capacities, proper conduct, and technical competency of individuals are developed to make them cultural members of their societies (Dorleku).

Pakistan is arguably the under developed country in the world. Although, still it face the considerable developmental challenges. There is increasing awareness that Pakistan will not be able to develop without adequate investment in people. Inequality in the distribution of these resources poses an additional challenge for the country. More often, there are inequalities along gender lines and between urban and rural divides and the government is focusing more on urban areas educational institutes and less on rural areas institutes (Olaniyan).

The idea of placement and displacement is directly linked to the diversity among broad radical. For example, Balochi and Sindhi students may share common cultural characteristics as a result of being Pakistani, but will also have distinctly Balochi and Sindhi cultural characteristics that differ from each other.

Moreover, the learning involves the transfer of prior knowledge and experiences on the bases of their cultural differences. To assist in this transfer process, it is important to acknowledge the students' background and to validate and incorporate their previous knowledge into the process of acquiring new information a teacher can play its very important role. That low-income students often perform poorly in academic tests is well known. But the fact that they do so because we systematically expect less from them. Mostly it is assumed that the low achievements of poor and low economic students are bound up on their families. The students don't try." "They have no place to study." "Their parents don't care." "Their culture does not value education." These and other excuses are regularly offered up to explain the achievement gap that separates poor and minority students from other areas other than urban (Saravia-Shore).Teachers have a particular responsibility to recognize and structure their lessons to reflect student differences. Teaching is the main way of promoting learning and achievement among students but teaching and learning are what affect knowledge, skills, attitudes, and the capacity of young people to contribute to contemporary societies (K.).This encourages students to recognize themselves and others as individuals. It also encourages the appreciation of a diverse institution population and brings a sense of connection between disparate cultural heritages within a single institution culture. It is certainly in the best interest of students and teachers to focus on the richness of our diversity ( $\mathrm{LYNCH}$ ). It is a positive image of education among students and helps them to struggle for their future. Yet, rural areas institutions are deficient in basic facilities and need to be given more attention, so as to bring them at par with rest of the institutions.

\section{PROBLEM IDENTIFICATION}

In Pakistan, a very short list of students with the top positions is from the low economic side. Competent and hardworking students facing barriers to get their deserving place. People are working to remove this factor and many organizations are also contributing but still much more is needed. Students are facing problems in career development after their completion of studies just because of the discriminatory attitude that students from rural areas cannot perform well in the work place. Organizations can get better output by promoting different cultures. Many studies reveal that students from rural culture are struggling hard to break this notion but still, this factor is effecting their career development in private and public sector of Pakistan. This study was conducted to examine the invisible barriers in the way of student's career development in different sectors. This study also explored the ways to reduce these barriers and main reasons of these hurdles for their career development and enhance the role of institutions in their grooming.

\section{PROBLEM STATEMENT}

The economic, social and educational diversity in the country like Pakistan, can hinder smooth career development of students. The increasing gap with in the society may influence the future course of behavioural transformation of the new generation. 


\section{OBJECTIVES OF THE STUDY}

Following are the objectives of the study.

1. The study will provide an insight to mitigate the gap between the different segments of the society.

2. To investigate the impact of cultural diversity on students career development.

3. To evaluate the relationship between students career and institution role.

\section{SIGNIFICANCE OF STUDY}

In third world countries, the social and economic disparities have resulted in the creation of Haves and Have nots in the society. A study was carried out to highlight the reasons for social and economic deprivation and recommend remedial measures for bridging the gap between Have and Have not's.

\section{LIMITATIONS}

1. Findings from this research paper may not be generalized beyond the educational institutions participating in the study.

2. It is impossible to identify all variables impacting student achievement, behaviour, attendance, dropout rate, and teacher turnover rate. This could result in error variance and less significant correlation in the identified variables.

\section{LITERATURE REVIEW}

Students develop their educational and occupational plans on the basis of their backgrounds and experiences. Their life experiences are determined by their family backgrounds. Specifically, students with less income background had low educational attainment, low occupational skills and knowledge, and get low occupational opportunities and have little understanding of productivity. This section is included to provide insight, as evidenced by a review of pertinent literature, into the content of institutions facilities and their bearing on educational institute's improvement efforts.

According to Gray, Griffin, and Nasta (2005), students come to school with unique sets of characteristics that include cultural backgrounds that may assist or impede academic performance. Students confident in their own objectivity may overestimate their invulnerability to bias. Often students are generalized in groups and evaluated by the system or an individual. Adding diverse background students to homogenous environments of the university does not create a more welcoming and intellectually stimulating campus.

The social identity of a student influences how they receive and perceive the instructions of an instructor. For Example, Students from far flung areas receive low teaching evaluations, as cultural diversity, is the main point of their learning process. Students complain about the International Faculty accents. Whereas, students from urban side establishing the credibility in the classroom because of their knowledge of English language.

According to Vishnu Subramanian, One of the main reason to choose the incredible diversity of students to study and share a campus with students from different cultural background has been an awful experience. Diversity has always been an important decision one can make for the career.

\section{RESEARCH METHODOLOGY}

The researcher collected through questionnaire disseminated to students, parents and general public and faculty. In this research six universities from the urban and five universities from the rural areas were selected for the study. Students with different backgrounds were randomly selected for the collection of data. Interviews were conducted with the faculty and the students, surely the ethics of research. The available literature on the subject was consulted by visiting numerous libraries and archives.

The study is based on descriptive qualitative design. The main purpose to conduct this research is to identify the impact of placement and displacement over the career of Pakistani students. The researcher used survey method for collection of data from targeted population. Although the study will be considered as a descriptive type of study researcher also collects many primary data. The researcher wanted to know about attitudes, reactions of working employees, personal experiences of employees regarding this barrier.

\section{DATA COLLECTION PROCEDURE}

Data is collected through the structured questionnaire to identify the impact of diversity on student's career development. There were two sections of the questionnaire. The first section provided demographic 
information while the second section consisted of questions regarding the career of students.

\section{DATA ANALYSIS}

Pakistan, with approximately 176 million people is the sixth largest country in the world. It is linguistically extremely diverse country. The national language Urdu, of Pakistan, is the mother tongue of a minority of the population. Urdu is the official language and it is used extensively in urban areas and it is also the language of institutions, but only in low economic status areas. Mostly for private institutes, local languages were neglected and the English language becomes the language of power and prestige.

Institutions in Pakistan fall into five categories. The defining characteristics of which is the medium of instruction that is used:

- Elite private institutes are modelled on Oxford curriculum, fees are extremely expensive, and the medium of instruction is the English language.

- Educational Institutes run by the armed forces also use the English language as a medium of instruction.

- Government schools serve the mass of the population in Pakistan. No fees are charged. The medium of instruction in most parts of the country is the Urdu language. Although the Sindhi language is used in Sindhi schools, other local languages are used in Khyber Pakhtunkhwa like Pashtu language.

- The rise of non- elite English medium institutes is observed in recent years which charge modest fees.

- Madrasas a very heterogeneous category of institutions and their language practices are also varied. They provide an education towards religious studies. Some charge no fees and this become the attraction for low economic class.

The language names used in this report are the standard names used by Pakistanis. People use different languages. Standard names, ISO codes and alternative names of languages discussed in this report.

\begin{tabular}{|l|l|l|}
\hline Standard Name & ISO Code & Alternative Names \\
\hline Balochi & {$[$ bgp $]$} & Baluchi \\
\hline Punjabi & {$[$ pun $]$} & Punjabi \\
\hline Urdu & {$[$ urd $]$} & Urdu \\
\hline Sindhi & {$[$ snd $]$} & Sindhi \\
\hline Pashtu & {$[$ Psu $]$} & Pashtu \\
\hline
\end{tabular}

It is difficult for students to manage different languages at a time. Students use the mother tongue to strengthen the link between home and institute. Their sense of identity is validated and strengthened if the language of home and the language of the institute are the same. Students find learning enjoyable if it takes place through a language with which they are already similar and it takes place a more active role in their learning. It is considered in Pakistan mother tongue contributes to the maintenance of the survival. If languages are lost, they considered as the loss of identity. And if the language death occurs, the speaker respect is tarnished (Capstick).

A sample of 432 students was taken from five top private universities of Islamabad to evaluate their insight toward dimensions of higher education. The findings show that status of students for scholarship, extracurricular activities, parents' education, age, previous result, and university they study in having a significant influence on perception about the quality of education in institutes.

Survey of fives universities indicates student learning both in-class and out-class interactions and involvements with diverse culture peers. The research study shows that's the university environment is radically non-discriminatory and it seems difficult for the students only to accept both diversity and intellectual challenge. Faculty members are considerably less satisfied with their jobs.

The survey shows that rural and urban students had comparable levels of achievement in some of the tested learning areas In Punjab and Sindh, urban students performed significantly better in social studies and language tests; scores on social studies and language did not differ significantly across location in the North West. The differences appeared to be partly explained by variation in institution 
conditions, student's home background, and teacher's characteristics. Teachers training turned out to be decisive in determining student's achievement, whereas the availability of resources and multigrade teaching was less important. The study has employed an appropriate sampling strategy and proportionally adequate sample to address the potential differences in achievement of rural and urban students in four provinces. The findings could, therefore, be used to guide policy interventions in areas of curriculum differences, institution conditions, teachers training and multi-grade teaching across provinces in Pakistan (Tayyaba).

\section{RESULTS}

A sample of 430 students of the session 2017 was enrolled in the study When the academic performance of the sample was compared a significant difference was found in urban and rural students. This research paper has examined rural and urban differences in their achievement. Usually, it is believed that students from rural institutes mostly receive an education that is inferior compared to the students that live in urban areas. Because urban students are provided with better quality in education, availability of the information that they get from various sources like electronic media and mass media, their educated families and peers groups which also help them for better performance. They have many facilities and advantages in their education compared to rural students. Students in rural areas are less exposed to the outside world and also there is lack of knowledge about the current issues that they come across. It is clearly indicative of the research paper that the locality has a significant effect on the academic performance of the students (Mateen)

\section{CONCLUSION}

The collected data clearly illustrates the fact that in the third world countries, the grouping and the segregation of regions and academic courses have contributed to the existing issue. Students with rural background fail to comprehend the concepts given at higher level due to curriculum differences. Furthermore, the lack of national integration of curriculum also gives rise to the poor quality of education and thus hampers career development.

\section{REFERENCE LIST}

Capstick, Hywel Coleman and Tony. "Language in Education in Pakistan." (2012 ).

Dorleku. "Teaching and learning in border towns: A study of four junior high schools along the Ghana-Togo Border (Master's thesis)." (2013).

K., Mangal S. "Essentials of educational psychology." ((2007)).

Lynch, Matthew. "4 REASONS WHY CLASSROOMS NEED DIVERSITY EDUCATION." The Edvocate (2016).

LYNCH, MATTHEW. "The Edvocate." (n.d.).

Mateen, Hajra. "Evaluation of the academic achievement of rural versus urban." Asian Specific Journal of Reproduction (2016).

Olaniyan, Segun Olugbenga Adedeji and Olanrewaju. "Improving the education and teaching in Institutes." UNESCO-IICBA (2011).

Rizwan Faisal, Laiyla Shinwari. "Evaluation of the academic achievement of rural versus urban undergraduate medical students in pharmacology examinations." Asian Pacific Journal of Reproduction 5 (2016): 317-320.

Saravia-Shore, Marietta. Diverse Teaching Strategies for Diverse Learners. Alexandria, 1995.

Tayyaba, Saadia. "Rural-urban gaps in academic achievement, schooling conditions, student, and teachers' characteristics in Pakistan." International Journal of Educational Management 26 (2012): 6-26 . 